\title{
Study on the soft power of Chinese petroleum enterprises
}

\author{
Guo Siliang ${ }^{1, ~ *, ~ D i a o ~ Y a n h u a ~}{ }^{1,2}$ \\ ${ }^{1}$ Qilu Normal University, College of Economics and Management, Shandong, China \\ ${ }^{2}$ Dhurakij Pundit University, Chinese International College, Bangkok, Thailand \\ Email address: \\ GSL200601@126.com (Guo Siliang), diaodarling@126.com (Diao Yanhua)
}

\section{To cite this article:}

Guo Siliang, Diao Yanhua. Study on the Soft Power of Chinese Petroleum Enterprises. International Journal of Economic Behavior and Organization. Vol. 2, No. 6, 2014, pp. 78-82. doi: 10.11648/j.ijebo.20140206.11

\begin{abstract}
The paper, basing on the factors that influence the construction of the soft power of the Chinese petroleum enterprises, puts forward the countermeasures and suggestions to enhance the soft power of the petroleum enterprises from various aspects, including the construction of the enterprise culture, strengthening of the resource integration, promotion of the innovation ability, fulfillment of the social responsibility, strengthening of the management control, and shaping of the image.
\end{abstract}

Keywords: Petroleum Enterprise, Soft Power, Promotion

In today's economy and society, soft power has become an essential element of economic development. Soft power is the ability of enterprises and enterprise relatively hard power, integration and use of hard power. Soft power is essential to support the development of enterprises, is the ultimate business operations to maximize the effectiveness of key competencies. Soft power generally includes corporate culture, enterprise system, business execution, corporate image, brand and other intangible factors. Petroleum enterprises are one of the highly specialized businesses, to achieve higher efficiency in the management. Improve the overall strength of the enterprise. It is necessary to pay attention to the soft power of the petroleum enterprises, so that the core competitiveness of enterprises will be further improved.

\section{Connotation of Soft Power of Petroleum Enterprises}

\subsection{Literature Review}

Soft Power was first proposed by Joseph S. Nye of Harvard University in 1990. His article on "Foreign Policy" magazine published entitled "soft power"; the first clearly stated and explained the concept of "soft power". Since Joseph S. Nye's soft power theory come out so far, constantly enrich its content.

Country's increasing emphasis on soft power, soft power theory has been increasingly used in the field of multi-level strategic competition between nations like. However, just in terms of foreign scholars, the study of soft power is relatively limited, common in the country's soft power, little soft power in other areas of research.

In recent years, soft power as a theory, has been widespread concern in academic circles, but also further enrich its content, its ideology has been the promotion and extension of international relations in a number of similar areas in the competition, the internationalization and competition in the field of business diversification is one of them, thus, soft power is becoming a widely accepted concept.

At present, in China, the concept of soft power is being managers and scholars engaged in the study of some oil company's oil companies recognized and accepted. However, studies of soft power is still limited to the three major oil companies oil companies and related management researchers, and most of the soft power of limited corporate culture construction, reducing the scope of the study the basic theory of soft power Nye, pending further study.

China Petroleum Chen Jidong (2009) considered the soul of soft power is to ensure sustainable and stable development of the oil companies must focus on strengthening the guidance of corporate culture, brand reputation force, management innovation, social affinity and efficient integration capability to integrate force of five constructions, enhance the soft power.

Five experts China National Petroleum Corporation's Policy Research proposes ten categories constitute soft 
power factor oil companies, including strategic winning force, technological innovation, decision-support force, the force of talent development, risk control, team execution, culture power management, management control, business development force, the Combination force, and explore appropriate ways to build and upgrade.

\subsection{Connotation Define}

Combined with the current domestic scholars on the study of soft power and soft power theory of oil companies, the research puts forward some of his own views on the oil companies of soft power.

Soft power of petroleum enterprises refers to the nonmaterial force which, basing on the hard power of the Petroleum Enterprises, through the occupation and transformation of the hard power like technological means as well as the spreading of the specific soft resources like harmonious and dedicative corporate culture, affects the stakeholders and other social objects and makes them recognize, accept and support the enterprises so as to realize the expected target of the petroleum enterprises. The soft power of petroleum enterprises is the key factor for the petroleum enterprises to enhance the hard power, develop into the internationalized energy enterprise, and realize sustainable development.

\section{Factors Affecting the Soft Power of Petroleum Enterprise}

The petroleum enterprises are the pillar industry for the development of the national economy. It is necessary to conduct deep analysis towards the factors affecting the construction of soft power, and further provide the basis for the promotion of the soft power of petroleum enterprises.

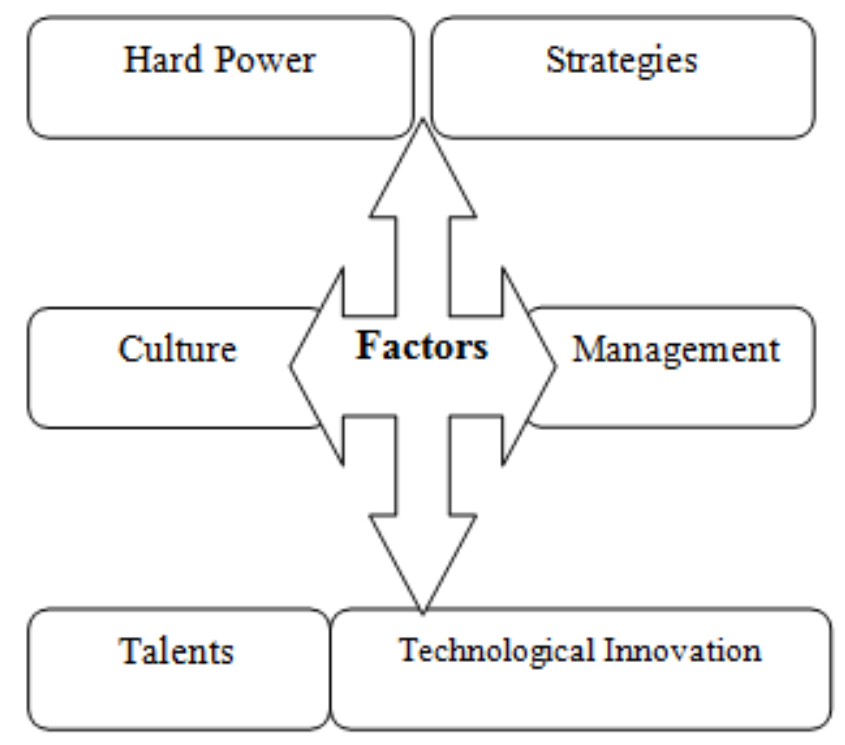

Figure 1. Factors Affecting the Soft Power of Petroleum Enterprise

\subsection{Hard Power of Petroleum Enterprise}

Hard power of petroleum enterprises such as capital and resources is the foundation and key for the formation of soft power which directly affects the soft power of the petroleum enterprises. Only when the hard power of the enterprises is accumulated to a certain extent, the enterprises can have enough capital and resources to build and enhance the soft power. At the same time, the hard power of the enterprises also affects the social cognition on enterprises and the further accumulation of both hard and soft resources. When the hard power of an enterprise is accumulated enough to affect the development of the industry and the related policies, the enterprise can drive various social resources through hard power to promote the soft power.

\subsection{Strategies of Petroleum Enterprises}

The enterprise strategy refers to that the enterprise chooses the products suitable to its own field and forms their own core competitiveness according to the environment change, its resources and strength, and finally wins in the competition through differentiation. The strategies of an enterprise affect its survival and development, playing an important role forming soft power.

With the acceleration of economic globalization and the integration process and the consequent international competition, business strategy requires higher. In a rapidly changing environment, companies must adjust their strategies to timely adapt to environmental changes. Effective development strategies will determine the competitive strength of the petroleum Enterprises. China's large state-owned petroleum Enterprises have attributes, while in the domestic oil market also has a monopoly, the national oil security responsibility undoubtedly falls on their shoulders. On this basis, the strengthening of the petroleum Enterprises need to fulfill the strategic petroleum governance has become corporate social responsibility, has become the petroleum Enterprises to fulfill economic responsibility, environmental responsibility and moral responsibility of the foundation and protection.

\subsection{Culture of Petroleum Enterprises}

The enterprise culture is the support and guarantee of the enterprise strategy, and even equates the soft power of the enterprise to some extent. With the social development, technological progress, and constantly changing social environment, the means to facilitate the enterprise construction and enhance soft power are constantly in change as well, which directly affects the formation and promotion of the soft power of petroleum enterprises.

\subsection{Management of Petroleum Enterprises}

The management level directly affects the development ability of an enterprise. Constantly improving the management level is the necessary condition for the sustainable development of an enterprise. With the rapid 
development of Chinese petroleum enterprises and the constant rise of the internationalization degree in recent years, it's becoming more and more difficult in management, and the soft resources are urgently needed in management. In one word, management has become increasingly important to the soft power of the petroleum enterprises.

\subsection{Technological Innovation of the Petroleum Enterprises}

Technological innovation is the fundamental driving force for the long-term sustainable development of a petroleum enterprise. There are four aspects of technological innovation, namely talent innovation, investment innovation, cultural innovation and mechanism innovation. The constant enforcement of the technological innovation of the petroleum enterprises can not only effectively reduce the cost of petroleum production, increase production and enhance the hard power of the petroleum enterprises, but also accelerate the development of new technology and new knowledge. Furthermore, it also affects the soft resources such as innovational environment and consciousness as well as the intangible basis of the soft power of the petroleum enterprises.

\subsection{Talents of Petroleum Enterprises}

Talents are the most important resource for the petroleum enterprises to move towards internationalization and globalization. Only the unified and optimistic talents personnel can bring strong innovation capacity to the enterprises, facilitate the enterprise development, bring vitality to the enterprise, and affect the formation and promotion of the enterprise soft power.

\section{Countermeasures to Enhance the Soft Power of Petroleum Enterprises}

With the development of society, in order to promote the soft power, the petroleum enterprises must conduct technology and management innovation, enhance their cultural power, innovation ability, social responsibility, resources integration, management control and corporate image, and ultimately improve the comprehensive power and international competitiveness.

\subsection{Construct advanced Culture of Petroleum Enterprises}

Corporate culture is an important part of the soft power of an enterprise's core competitiveness, but also the petroleum enterprises to achieve an essential element for further development. Culture soft power index which has been incorporated into national development strategies.

In recent years, petroleum enterprises in achievements, but also there are a lot of pollution, seriously affecting the development of society, and even endanger the safety of human life. Therefore, to strengthen cultural soft power of petroleum enterprises is imperative. Taking into account the development of today's domestic and international situation, the petroleum enterprises want to develop strategies on the basis of the corporate culture, the establishment of specialized organizations, improve the relevant departments and leadership organizations.

In addition, petroleum enterprises and cultural work is an ongoing process of reform and innovation, corporate culture to maintain vitality, constantly learning new cultural ideas, and create a culture in the new situation in a timely manner to improve the content of the work culture and systems to meet the business and cultural development needs.

First of all, the petroleum enterprises has equipped with the unique characteristics of the petroleum enterprise spirit in the long-term production practice, such as the spirit of Daqing "Patriotism, Pioneering, Truth-seeking, and Dedication". With the development and progress of the times, the petroleum enterprises constantly explore the new connotation of enterprise spirit and lay a good foundation to continuously enhance corporate culture. Secondly, under the international circumstance, Chinese petroleum enterprises not only need to constantly improve their own culture and embodies the Chinese native culture in their enterprise culture, but also need to absorb the outstanding elements of international culture to enable the compatibility and openness. For the transnational merger and acquisition, petroleum enterprises must emphasize the talent management, widely introduce and cultivate enterprise management talents who are proficient in cross-cultural communication and international standards, emphasize the cultural integration, strengthen the management of culture risk, timely deal with cultural conflicts, and eliminate all kinds of problems influencing cultural integration as early as possible.

\subsection{Enhance the Innovation Capacity of the Petroleum Enterprises}

\subsubsection{Scientific Innovation}

Petroleum enterprises in the development, technological innovation are the fundamental driving force for development and essential factor. We should adhere to the sense of innovation throughout the work among the petroleum enterprises, in all aspects of the work focused on innovation, a regular cadre of business and professional training of employees, encouraging everyone to pursue innovation in their work. Petroleum enterprises is a high-tech enterprise, requires a lot of investment in technology and research, intellectual property issues are also increasingly prominent, and this should be valued. Petroleum enterprises in the process of innovation and technology, the need to draw extensively on domestic and foreign advanced concepts, technology and experience, combined with their own actual situation, learn from each other.

Scientific innovation is the foundation and decisive factor for the development of the petroleum enterprise. Constantly improving the scientific innovation of the petroleum enterprises is an important guarantee for the enhancement of the soft power of the petroleum enterprises. Petroleum enterprises shall have to make the strategy of scientific innovation and increase the investment for scientific 
innovation so as to provide a strong guarantee for the scientific innovation. Besides, the petroleum enterprises shall also need to improve the mechanism of the cultivation of the innovative talents and strengthen cooperation to establish the open system of scientific innovation.

\subsubsection{Management Innovation}

The management level directly affects the operation of the enterprises as well as the promotion of the enterprise soft power. Hence the relatively backward management system and mechanism needs to be transformed and the soft power which matches with the hard power needs to be established for the petroleum enterprises. Make clear the core of management, improve the management level of petroleum enterprises, speed up the institutional innovation and promote the management innovation of the petroleum enterprises.

\subsubsection{Knowledge Innovation}

Petroleum enterprises, as knowledge-intensive and technology-intensive enterprises, shall pay attention to the knowledge management, speed up the pace of knowledge management, master more core technologies and own more independent intellectual property rights to promote the knowledge innovation of the petroleum enterprises and set up the knowledge base for the promotion of the soft power. Furthermore, the petroleum enterprises also shall create a good atmosphere for sharing and integrating knowledge, accelerate the knowledge innovation, and strengthen the innovation power of the petroleum enterprises.

\subsection{Fulfill the Social Responsibility}

In the context of globalization, a country's energy security is not only an economic issue, but also a political and military issue. To ensure our national energy security is the social responsibility of the Chinese petroleum enterprises. The petroleum enterprises shall correctly grasp the development trend of the domestic and international energy in order to timely adjust their business strategies according to the national energy strategy and policy. At the same time, the petroleum enterprises must enhance their sense of social responsibility as the social responsibility is not a simple public welfare and social donation, but the full implementation of the economic responsibility, environmental responsibility and moral responsibility.

\subsection{Strengthen the Resource Integration}

\subsubsection{Integration of Human Resources}

Talent is an important component of business development; human resources are the basic elements necessary. The current state of talent development of petroleum enterprises is not optimistic. Business leaders and cadres should first have a positive attitude, do not take formal management.HR management must be good for each employee truly understand, with particular emphasis on the advantages of the staff and try to ensure its full play. Petroleum enterprises is one of the highly specialized companies, professionals must have strict entry exam, then they have to regular staff professional guidance and training, and then vocational assessment and examination results and employee income linked incentives emphasis on improving the skills of employees. In addition, the soft power need to cooperate to strengthen the leadership and staff, mobilize the enthusiasm of the staff.

The long-term mechanism of talents training is necessary to promote the growth and the soft power of the petroleum enterprises. The petroleum enterprises train their stuff according to the need of market competition and put them in positive competition environment. In addition, it is necessary to establish learning team inside the enterprises, which is the necessary condition for the petroleum enterprises to enhance their soft power.

\subsubsection{Integration of Information Resources}

The petroleum enterprises should pay full attention to the management of sharing technology, play the role of the team, improve the ability of collecting and processing information through the application of advanced technology, and finally improve the ability of information integration ability of the petroleum enterprises.

\subsection{Strengthen the Power of Control}

Strengthening the internal control and management is the guarantee to ensure the safety and integrity of the enterprise resources as well as the reliability and validity of economic information. When strengthening the management and control, the petroleum enterprises should consider the characteristics of the petroleum industry, improve the management system, and emphasize the strategic management and control while taking into account the financial control and management control at the same time. In addition, the petroleum enterprises also should actively strengthen the ability of risk control.

\subsubsection{Improve enterprise planning system}

Strategic planning is guiding the development of the standard petroleum enterprises; more important is the content of the implementation of planning objectives and results.

First, petroleum enterprises should seriously study and improve enterprise management system, the system should be specific to the implementation of the program, the execution plan in place to ensure effective implementation, and execution team staff need to conscientiously implement the business planning requirements, and ultimately goal of becoming the implementation results;

Second, the petroleum enterprises have to keep the spirit of the times, with the development of society, and constantly improve the strategic planning of the content, so the planning system to keep pace with the times.

\subsubsection{Increase corporate supervision}

Implementation of corporate planning content to rely on the regulatory system. Petroleum Enterprise Association to strictly play its management functions. Petroleum enterprises need to strengthen the supervision and management of specific steps to implement the strict supervision of the 
regulatory responsibilities to individuals. Petroleum enterprises in the management should be standardized as much as possible to avoid loopholes in the management system, so that enterprises have specific rules and regulations to follow. To strictly controlled, so that violators are prosecuted strictly enforced.

\subsection{Shape Enterprise Image}

The social responsibility, service attitude, integrity and public relations of the petroleum enterprises will have an impact on the enterprise image. To enhance the soft power of the petroleum enterprises, it is necessary to strengthen the establishment of enterprise image and improve the enterprise image. Firstly, we must attach importance to the shape of the image of enterprise staff and the standardization of their words and deeds. Secondly, we also must attach importance to the image of the core leaders, and enable the entrepreneurs to become influential and charming. Thirdly, with the popularization of the network, the petroleum enterprises should improve their network control ability, maintain a good image, and build good network reputation.

\section{Conclusion}

With the development of society, it is the information age and knowledge economy era. Development of the oil companies can no longer rely solely resources, capital, technology and labor inputs, but also to fully recognize the important role of soft power for enterprise development. China's oil companies to complete the two changes, promoting the internationalization process, we must pay attention to the construction of soft power.

As a pillar industry of the national economy, the strength of the soft power of the oil companies will have a direct impact on the sustainable development of the oil companies and their international competitiveness, the soft power of oil companies building a more direct impact on the country's soft power building.

From the study of soft power abroad, the country's soft power, to domestic research on soft power; soft power has been domestic widely accepted theory and business circles. Under the background of economic globalization, China's Petroleum Enterprises want to complete the transformation, promoting the internationalization process; companies need to fully recognize the important role of soft power for enterprise development. As a pillar industry of the national economy, the strength of the soft power of the Petroleum Enterprises will have a direct impact on the sustainable development of the Petroleum Enterprises and their international competitiveness, Petroleum Enterprises soft power is directly related to the construction of the country's soft power.

In this paper, basing on the factors that influence the construction of the soft power of the Chinese petroleum enterprises, puts forward the countermeasures and suggestions to enhance the soft power of the petroleum enterprises from various aspects, including the construction of the enterprise culture, strengthening of the resource integration, promotion of the innovation ability, fulfillment of the social responsibility, strengthening of the management control, and shaping of the image.

\section{Acknowledgements}

First of all, thanks to Joseph S. Nye put forward the concept of soft power, and provide us with a new idea of a study. Secondly, thanks to Yang Jinbao for systematic study of Chinese soft power oil for writing my article provides a reference.

This paper is the research findings of the present stage of Research and development projects of Shandong Province Universities (project number : J14WF69)and Humanities and Social Sciences Project of Shandong Province (project number: 14-zz-wh-04).Project name is the new culture based on the advantages of Qilu Culture Perspective of Soft Power. These two projects, one based paper studies provide appropriate financial support; on the other hand, members of the research team collected a wealth of information about soft power, as of this writing, the information provided.

\section{References}

[1] Joseph S. Nye, Jr."Soft Power". Foreign Policy. 1990

[2] Joseph S Nye Jr.Soft Power: The Means to Success in World Politics. Journal of Women s Health. 2004

[3] Yang Jinbao. The Strategy Study on Evaluation and Promotion of Soft Strength of Petroleum Enterprise [D]. Northeast Petroleum University, 2012

[4] Hu Youqing. Some Problems Should Be Solved In the Construction of Petroleum Enterprise Soft Power [J]. Chinese Petroleum Enterprises, 2012, 09:84.

[5] Chen Jidong. Problems of Petroleum Enterprises to Enhance the Soft Power [J]. Beijing Petroleum Management College Journal, 2009, 01:13-19.

[6] Guo Enjing. The Soft Power of Petroleum Enterprise: Decision Support Force [J]. Petroleum Science and Technology Forum, 2010, 01:8-10+71.

[7] Wei Yanhong. The soft power of the Petroleum Enterprises Management -Cultural Innovation in $[\mathrm{J}]$ Oriental Culture, 2013, 16: 91 .

[8] Kang Juan. Petroleum Enterprises strengthen cultural soft power [J] providers, 2013, 12: 82 .

[9] Taoyin Sheng. Petroleum Enterprises how to enhance the soft power of community cultural development [J] managers, 2013, 21: 203 . 